\title{
Controvérsias sobre a revisão ética de pesquisas em ciências humanas e sociais pelo Sistema CEP/Conep
}

Adriana Silva Barbosa ${ }^{1}$, Carlos Montero Corrales ${ }^{2}$, Marcos Silbermann ${ }^{3}$

\section{Resumo}

O comitê de ética em pesquisa tem como função revisar todas as pesquisas envolvendo seres humanos realizadas no Brasil, o que tem suscitado controvérsias sobre a revisão ética de pesquisas em ciências humanas e sociais. O objetivo deste artigo é discutir as controvérsias da revisão ética de pesquisas dessas áreas no Sistema CEP/Conep. São controvérsias o biocentrismo, as melhorias pontuais da Resolução 466/2012, a emergência de um sistema paralelo de revisão ética para essas áreas ou a constituição de resolução complementar própria no Sistema CEP/Conep. Tais controvérsias relacionam-se com limitações funcionais dos comitês de ética: grande demanda de projetos, poucos comitês, limitações da Plataforma Brasil e necessidade de capacitação dos membros. O Sistema CEP/Conep deve continuar como único sistema de revisão ética em pesquisa brasileiro; mas necessita que as resoluções sejam continuamente revisadas para contemplar as especificidades das pesquisas das áreas humanas e que sejam criados mais comitês com melhor capacitação.

Palavras-chave: Comitês de ética em pesquisa. Comissão de ética. Revisão ética. Ética em pesquisa. Ciência. Ciências humanas. Ciências sociais.

\section{Resumen}

Controversias sobre la revisión ética de la investigación en ciencias humanas y sociales por el Sistema CEP/ Conep

El Comité de Ética en Investigación debe revisar todas las investigaciones en seres humanos realizadas en Brasil, lo que ha causado controversias acerca de la revisión ética de la investigación en ciencias humanas y sociales. El propósito de este artículo es discutir las controversias de la revisión ética de la investigación en estas áreas en el Sistema CEP/Conep. Las controversias son el biocentrismo, las mejoras puntuales en la resolución 466/2012, la aparición de un sistema paralelo de revisión ética para estas áreas o la constitución de una resolución complementaria propia en el sistema CEP/Conep. Estas controversias se refieren a las limitaciones funcionales de los Comités de Ética: gran demanda de proyectos, pocos comités, limitaciones de la plataforma Brasil y la necesidad de capacitación de los miembros. El sistema CEP/Conep debe continuar como único sistema de revisión ética en investigación brasileña; pero requiere que las resoluciones sean revisadas continuamente para contemplar las especificidades de las investigaciones en las ciencias humanas y ciencias sociales y que sean creados más comités con mejor formación de los participantes.

Palabras-clave: Comités de ética en investigación. Comités de ética. Revisión ética. Ética en investigación. Ciencia. Ciencias Humanas. Ciencias Sociales.

\section{Abstract \\ Controversies on the ethical review of research in the Humanities and Social Sciences by System CEP/Conep} The Ethics Committee must review all researches involving human subjects conducted in Brazil, which has caused controversies about the ethical review of research in the humanities and social sciences. The purpose of this article is to discuss the controversies of the ethical review of research in these areas in System CEP/ Conep. The controversies are the biocentrism, the punctual improvements in Resolution 466/2012, the emergence of a parallel system of ethical review for theses areas or the constitution of supplementary resolution in the system CEP/Conep. These controversies relate to functional limitations of the ethical committees: high demand of projects, few committees, limitations of the Brazil platform and the need for members training. The System CEP/Conep should continue as the only system of ethical review in Brazilian research; but it requires that the resolutions are continually revised in order to include the specificities of the researches in the humanities and create more committees with better training.

Keywords: Ethics committees, research. Ethics committees. Ethical review. Ethics, research. Science. Humanities. Social Sciences.

1. Doutoranda drybarbosa@yahoo.com.br 2. Mestrando carlos.monterocorrales@gmail.com 3. Doutorando meirsi@gmail.com Universidade Estadual de Campinas (Unicamp), Campinas/SP, Brasil. 
O objeto de estudo deste artigo são as controvérsias sobre a revisão ética de pesquisas em ciências humanas e sociais pelo Sistema CEP/Conep, vez que todas as pesquisas envolvendo seres humanos, independentemente da área do conhecimento científico, devem ser eticamente revisadas por comitê de ética em pesquisa (CEP).

A relação entre ciência, tecnologia e ética merece especial atenção no que concerne ao controle social em pesquisa, pelo fato de esse controle estar ligado aos fundamentos da política científica e tecnológica desenvolvida no Brasil, já que as pesquisas têm grande importância para o desenvolvimento social, científico e econômico de um país, podendo contribuir para melhorias sociais, educacionais, da saúde e das condições de vida da população. Isso significa que o fazer científico desenvolve-se em contextos cujas determinantes culturais estão em constante e acelerada construção, apresentando desafios à compreensão do papel do cientista na sociedade, da realidade na qual empreende suas pesquisas, bem como à implementação de controle social de pesquisas nas diversas áreas do conhecimento.

A compreensão de que os cientistas são seres humanos, cujo comportamento ético é constructo dinâmico e evolutivo, e a existência de várias áreas do conhecimento científico, com múltiplas formas de conceber e fazer pesquisa, evidenciam os desafios que o Sistema CEP/Conep precisa enfrentar para estabelecer controle social em pesquisa que leve em conta as especificidades de todas essas áreas do conhecimento, de maneira a aumentar sua resolutividade, uma vez que os CEP se fazem cada vez mais necessários e presentes na construção da relação entre a ética, a ciência e a tecnologia.

Nesse contexto, é importante lembrar que o Sistema Nacional de Revisão Ética de Pesquisas Envolvendo Seres Humanos, mais conhecido como Sistema CEP/Conep, foi criado pela Resolução 196/1996 ${ }^{1}$ e é formado por uma instância nacional, a Comissão Nacional de Ética em Pesquisa (Conep) e pelos CEP. Substituta da Resolução $1 / 1988^{2}$, voltada apenas para pesquisas na área de saúde e sem maiores efeitos práticos, a Resolução 196/1996 foi elaborada por um Grupo Executivo de Trabalho (GET), após amplo processo de consulta pública, e destinava-se, entre outras coisas, a regulamentar as atividades de pesquisa envolvendo seres humanos realizadas nas diversas áreas do conhecimento científico no país ${ }^{1}$.

Apesar de sua aplicação prática, a Resolução 196/1996 necessitava de revisão, para poder acom- panhar as transformações do mundo científico e do próprio Sistema CEP/Conep, bem como para tornar mais ampla a concepção de pesquisa e atender às especificidades das pesquisas não biomédicas, no intuito de dirimir as controvérsias geradas pela tramitação das pesquisas dessas áreas no sistema. Assim, em 2011, foi realizada consulta pública a fim de que toda a sociedade pudesse contribuir com sugestões para a revisão da resolução. O material coletado nessa consulta foi analisado por um grupo de trabalho e as conclusões da análise apresentadas em 2012 no 10 Encontro Extraordinário dos Comitês de Ética em Pesquisa, realizado em São Paulo $^{3}$. Como resultado desse esforço, foi homologada pelo Conselho Nacional de Saúde a Resolução $466 / 2012^{4}$, que manteve a estrutura organizacional do Sistema CEP/Conep e trouxe avanços pontuais ao sistema, entre os quais a previsão de elaboração de resolução complementar para as pesquisas em ciências humanas e sociais.

Instância nacional do Sistema CEP/Conep vinculada ao CNS, a Comissão Nacional de Ética em Pesquisa é órgão colegiado de natureza consultiva, deliberativa, educativa e independente, cuja composição, multi e transdisciplinar, é formada por 30 membros titulares e 8 suplentes de ambos os sexos. Dentre suas funções, distinguem-se: estímulo à criação de comitês de ética em pesquisa; aprovação e acompanhamento de projetos de pesquisa das áreas temáticas especiais (que não tenham legislação específica e/ou necessitem da apreciação da Conep para ser desenvolvidos); elaboração e divulgação de normas específicas no campo da ética; constituição de sistema de informações e acompanhamento dos aspectos éticos das pesquisas envolvendo seres humanos ${ }^{1,3-6}$.

Os CEP são órgãos regionais colegiados, interdisciplinares, interdependentes, investidos de múnus público, que integram os mecanismos de controle social organizado com o intuito de buscar tratamento humanizado para os participantes da pesquisa. Além disso, têm como missão salvaguardar os direitos e a dignidade dos participantes da pesquisa, para que seus interesses sejam considerados acima dos interesses da ciência e da sociedade, notadamente de grupos sociais mais poderosos. Suas funções abrangem, entre outras: revisão dos protocolos de pesquisa envolvendo seres humanos; emissão de parecer consubstanciado dos projetos de pesquisa aprovados; desempenho de papel consultivo e educativo; recebimento de denúncias sobre violação de aspectos éticos por parte de pesquisas envolvendo seres humanos; comunicação contínua com a Conep ${ }^{1,4,7}$. 
A primeira tentativa de informatização do Sistema CEP/Conep foi o Sistema Nacional de Informação sobre Ética em Pesquisa (Sisnep), que constituía um meio de comunicação por internet de informações requeridas pelos CEP, pesquisadores, Conep e população em geral. O Sisnep foi criado, entre outras finalidades, para: Facilitar o registro das pesquisas envolvendo seres humanos e orientar a tramitação de cada projeto [...]; integrar o sistema de avaliação ética das pesquisas no Brasil (CEPs e Conep) [...]; agilizar a tramitação e facilitar aos pesquisadores o acompanhamento da situação de seus projetos [...]; permitir o acompanhamento dos projetos já aprovados [... ${ }^{8}$. Todavia, esse sistema limitava-se ao preenchimento das folhas de rosto dos projetos de pesquisa envolvendo seres humanos e à informação do resultado final da revisão ética dos projetos, e nunca chegou a incluir todos os CEP ativos no Sistema CEP/Conep.

No ano de 2012, o Sisnep foi substituído pela Plataforma Brasil, sistema on-line de revisão ética dos projetos de pesquisa envolvendo seres humanos que registra todo o processo de trabalho do Sistema CEP/Conep por meio dos módulos público, CEP, Conep e pesquisador. Nesse sistema, é possível aos pesquisadores preencher os dados dos projetos, inserir toda a documentação pertinente, submeter o projeto ao CEP, acompanhar seu andamento no sistema, receber o parecer consubstanciado logo após a realização da reunião, responder às pendências apontadas nos projetos, iniciar o processo de acompanhamento dos projetos aprovados e encaminhar relatórios. Ao CEP e à Conep cabe encaminhar os projetos aos pareceristas, revisar os projetos, redigir pareceres, inserir a pauta e realizar reuniões, elaborar atas das reuniões, analisar as respostas às pendências, apreciar as notificações e emendas (acompanhamento dos projetos aprovados), enviar pareceres consubstanciados aos pesquisadores e analisar e emitir pareceres sobre os relatórios enviados pelos pesquisadores. Além disso, em sua página inicial, os números de projetos submetidos aos CEP e à Conep estão disponíveis para consulta pública.

Nesse contexto, considerando que o Sistema CEP/Conep deve apreciar todas as pesquisas envolvendo seres humanos realizadas no Brasil, a multiplicidade de disciplinas e a interdisciplinaridade (compreendida como esforço para correlacionar disciplinas ${ }^{9}$ ) de saberes envolvidos nas pesquisas constituem-se em desafios à conformação dos critérios éticos do Sistema CEP/Conep como responsável pelo controle social das pesquisas envolvendo seres humanos. Tais desafios nos apresentam um campo de estudo de relevância social, em que a forma como o sistema institucionaliza o fazer ético nas pesquisas encontra-se suscetível a mudanças que permitem facilitar o diálogo entre os CEP e os pesquisadores. Isso se deve aos vários métodos e teorias utilizados em pesquisa nas diversas áreas do conhecimento científico, tornando importante, portanto, a discussão das controvérsias sobre a revisão ética de pesquisas em ciências humanas e sociais no âmbito do Sistema CEP/Conep.

Assim, o presente trabalho tem como questão norteadora: quais são as controvérsias sobre a revisão ética de pesquisas em ciências humanas e sociais no Sistema CEP/Conep? Para responder a esse questionamento, elaboramos o seguinte objetivo: discutir as controvérsias sobre a revisão ética de pesquisas em ciências humanas e sociais no Sistema CEP/Conep, a fim de evidenciar seus desafios e possíveis alternativas à construção mais abrangente da dinâmica tecnociência-ética-cientista, tendo em vista a forma como os CEP institucionalizam a delimitação teórico-conceitual do fazer ético nas pesquisas desenvolvidas no Brasil.

\section{Método}

Este artigo de atualização emergiu de discussões sobre a revisão ética de pesquisas em ciências humanas e sociais no contexto da disciplina Introdução à Política Científica e Tecnológica, do Programa de Pós-Graduação em Política Científica e Tecnológica da Universidade Estadual de Campinas (PPG-PCT/ Unicamp). Para subsidiar nossa discussão, foram selecionados dez artigos a partir das buscas realizadas nas bases de dados Google Acadêmico, SciELO e Portal Capes, entre os meses de maio e julho de 2014, empregando como palavras-chave os seguintes termos: "Comitê de ética em pesquisa"; "Comitê de ética em pesquisa em ciências humanas"; "Resolução complementar para ciências humanas"; "revisão ética"; "revisão ética em pesquisa e sistema específico de revisão ética para ciências humanas". Utilizamos também livros, uma dissertação de mestrado, uma tese de doutorado, as resoluções-mãe do Sistema CEP/Conep (a revogada Resolução 196/1996 e sua substituta, a Resolução 466/2012) e outras resoluções que se mostraram relevantes para o estudo. Além disso, visitamos os sites da Conep, do Ministério da Educação (MEC), da Associação Brasileira de Antropologia ( $A B A$ ) e do Comitê de Ética em Pesquisa em Ciências Sociais da Universidade de Brasília (CEP/IH/UnB). 
Controvérsias na revisão ética de pesquisas em ciências humanas e sociais

\section{Processo de revisão ética das pesquisas}

Diferentemente das ciências exatas e biomédicas, que costumam firmar-se em pretensa neutralidade, anunciada nas relações estabelecidas entre sujeito e objeto, os métodos e procedimentos empíricos das ciências humanas e sociais são tidos como inerentemente éticos, vez que são realizados a partir e através do estabelecimento de relações com outros seres humanos. O cientista social está continuamente construindo perspectivas entre identificação e distanciamento, entre sentidos e reconhecimento, relações sobre as quais a postulada neutralidade não pode ser pretendida em seu sentido simples. Como diria Rabinow ${ }^{10}$, seu fio condutor é ético não por referir-se a um código de conduta exterior à pesquisa, mas por explicitar a condição complexa em que se coloca o pesquisador: situação de interdependência com o pesquisado e com a realidade complexa, da qual ambos participam. Em outras palavras, a pesquisa nas ciências humanas tem por característica a construção desses espaços complexos, espaços in between ${ }^{10}$, que expõem seu viés ético. É nesses termos que a participação de cientistas sociais em comitês de ética em pesquisa e a elaboração de código de ética próprio devem ser consideradas.

Disso se depreende que a revisão da Resolução 196/1996 e sua transformação em Resolução $466 / 2012$ tornou mais evidentes as controvérsias sobre a revisão ética de pesquisas nas áreas de ciências humanas e sociais pelo Sistema CEP/Conep. O processo desvelou os limites do sistema diante das especificidades das áreas não biomédicas e a necessidade de mudar a maneira como se estabelece a relação ética entre as áreas do conhecimento, nas dimensões institucional e formal na dinâmica dos CEP. Com isso, busca-se adequar cada vez mais a atuação dos CEP, dado que esses comitês são forma contingente de responder a questões éticas colocadas pela pesquisa científica como fazer ético. Segundo De La Fare, Machado e Carvalho ${ }^{11}$, existe certo consenso crítico com relação às resoluções 196/1996 e 466/2012, tais como biocentrismo, formalização normativa (que engessa as pesquisas em ciências humanas e sociais), protocolos prescritos e aplicação rígida e compulsória do Termo de Consentimento Livre e Esclarecido (TCLE). Essas críticas podem ser exemplificadas pela revisão ética de projetos de pesquisa das áreas de ciências humanas e sociais com o emprego de parâmetros metodológi- cos próprios das áreas biomédicas e pela solicitação de TCLE em situações em que ele se torna inviável, como em pesquisas envolvendo contraventores ou no estudo de práticas consideradas ilícitas pela legislação brasileira, como o aborto.

Nesse sentido, é importante considerar que, nas resoluções 196/1996 e 466/2012, as controvérsias se encontram expressas também no uso do termo "pesquisa envolvendo seres humanos", dado que, de acordo com Oliveira ${ }^{12}$, o termo engloba pesquisas com e em seres humanos. A diferença entre uma e outra é que a pesquisa com seres humanos requer interlocução entre pesquisador e pesquisado, enquanto a pesquisa em seres humanos implica intervenção corpórea, ou seja, consiste em testes de medicamentos ou equipamentos sendo, portanto, pesquisa invasiva. Todavia, Porto ${ }^{13}$ alerta para o fato de que todo e qualquer tipo de pesquisa envolve pelo menos um ser humano, inclusive aquelas realizadas em animais ou que não têm nenhum ser vivo como objeto de pesquisa (como as pesquisas bibliográficas), já que o pesquisador que as realiza é ser humano. Além disso, a autora também lembra o caso em que as pesquisas não podem ser classificadas nem como pesquisa com seres humanos nem como pesquisa em seres humanos, a exemplo das pesquisas genéticas, que podem ser feitas a partir do recolhimento de material orgânico, como células da pele, fios de cabelo ou lascas de unha, fato que aponta a importância de considerar o termo "envolvendo" seres humanos na classificação dos estudos e suas implicações em termos de definição das estratégias éticas a serem adotadas para resguardar os participantes, sejam indivíduos ou comunidades.

Disso se infere que as controvérsias levantadas pela revisão ética de projetos de pesquisa de várias áreas do conhecimento no âmbito do Sistema CEP/ Conep trazem à baila as diferentes formas de conceber a pesquisa científica e sua realização como atividade ética, evidenciando a crescente necessidade de assegurar aos participantes a observação de cânones como integridade, beneficência, não maleficência, autonomia, entre outros. Isso significa que a necessidade de realização de pesquisas eticamente responsáveis, embora permeie implicitamente a discussão, deve ser salientada e reforçada e que o CEP, ao realizar a revisão ética dos projetos de pesquisa, contribui para que as pesquisas envolvendo seres humanos alcancem elevado padrão ético.

Essa revisão ética empreendida pelos CEP compreende o projeto de pesquisa em seu conjunto, centrando-se nos objetivos, na metodologia, nos instrumentos de coleta de dados e no Termo de 
Consentimento Livre e Esclarecido (TCLE) com a finalidade de proteger os participantes da pesquisa, tendo em vista a estreita relação entre esses itens constitutivos do projeto e a ética em pesquisa, já que, segundo Diniz e Sugai, as técnicas de pesquisa importam para a revisão ética, pois desvelam como os pesquisadores planejam recrutar os participantes, como será definida a participação e, no caso de estudos com risco além do mínimo, se os benefícios justificam efeitos ou danos aos interesses dos sujei$\operatorname{tos}^{14}$. Disso se depreende que a revisão ética dos CEP contribui para o aprimoramento ético-científico dos projetos analisados, assim como para seu desenvolvimento em padrões eticamente aceitáveis.

No âmbito das pesquisas em ciências humanas e sociais, é importante ressaltar que, embora existam diferenças em sua operacionalização, o método científico empregado tem tanto mérito quanto aquele utilizado nas ciências exatas e biomédicas, com a ressalva de que projetos das áreas de ciências humanas e sociais têm especificidades técnicas e podem, às vezes, exigir, mais sensibilidade do parecerista e do CEP para sua análise. Isso ocorre porque as resoluções que norteiam o Sistema CEP/Conep estão voltadas para as pesquisas biomédicas, aqui entendidas como aquelas que se situam nas áreas temáticas especiais dos Grupos I e II e em parte das áreas de conhecimento classificadas no Grupo III da folha de rosto para pesquisas envolvendo seres humanos, da Conep. Todavia, lembramos que essa classificação não esgota nem restringe as possibilidades de pesquisa nas áreas biomédicas e não biomédicas.

Segundo Diniz ${ }^{15}$, a sensibilidade do CEP ao lidar com diferentes formas de fazer pesquisa não significa cumplicidade com os pesquisadores, mas denota que o desafio da revisão ética nas ciências humanas e sociais compreende a identificação das implicações éticas presentes na opção metodológica de cada projeto em apreço, sem inquirir sobre o estatuto de confiabilidade das técnicas de pesquisa a ser empregadas pelo pesquisador.

\section{Limitações funcionais do Sistema CEP/Conep}

Outro aspecto que influencia as controvérsias da revisão ética dos projetos de pesquisa é a grande quantidade de projetos em processo de revisão pelos CEP, fato que, em nosso entender, provoca gargalos como a sobrecarga de trabalho aos pareceristas e a demora na apreciação de muitos projetos no âmbito do Sistema CEP/Conep, podendo levar à perda de financiamento e/ou ao comprometimento dos prazos para desenvolvimento de muitos projetos submetidos aos CEP, sejam eles das áreas de ciências humanas e sociais ou de outras ${ }^{16-18}$. Disso se infere que, apesar de contar com cerca de 684 CEP cadastrados ${ }^{19}$, o sistema ainda não dá conta de atender às 2.653 instituições de ensino superior do país ${ }^{20}$, vez que, além da demanda pela apreciação de projetos de pesquisa de pós-graduação, os comitês ainda têm de analisar os projetos de pesquisa da graduação, já que muitas instituições condicionam o trabalho monográfico da formação universitária à realização de pesquisa de campo.

Com muitos projetos a revisar e permeados por controvérsias devidas à variedade dos trabaIhos submetidos, muitos CEP não têm como realizar análise mais cuidadosa nem discussão plenária mais ampla, e acabam empregando generalizadamente, para as pesquisas em ciências humanas e sociais, os critérios avaliativos das pesquisas biomédicas, mais nitidamente adstritos às especificações das resoluções do Sistema CEP/Conep. Tal processo de transposição acrítica de parâmetros de apresentação e avaliação tende a gerar problemas para os pesquisadores, além de sobrecarregar ainda mais os CEP, que têm de revisar diversas vezes a mesma pesquisa até sua aprovação.

Nesse sentido, o advento da Plataforma Brasil promete aumentar a resolutividade do Sistema CEP/ Conep. Todavia, essa ferramenta tem sofrido críticas por parte de pesquisadores de diversas áreas do conhecimento, pois sua formatação permanece voltada para as pesquisas biomédicas, o que gera dificuldades para os pesquisadores das áreas de ciências humanas e sociais que precisam utilizá-la. A especificidade da plataforma reproduz-se nos CEP, cuja sensibilidade e conhecimento são essenciais para sugerir e acatar adaptações no preenchimento dos itens dos formulários disponibilizados pela plataforma, a fim de que seja possível apreciar projetos de áreas não biomédicas pertencentes às grandes áreas do conhecimento do Grupo III da folha de rosto da Conep: ciências exatas e da Terra, engenharias, ciências agrárias, ciências sociais aplicadas, ciências humanas e linguística, letras e artes. Cabe lembrar também que, no processo de implementação da Plataforma Brasil, não houve transição gradual do Sisnep e da documentação em papel para o formato completamente digital. Isso motivou numerosas críticas, pois muitos comitês demoraram a integrar-se e adaptar-se à plataforma, o que causou transtornos a sua dinâmica de funcionamento e aos pesquisadores, cujos projetos permaneceram pendentes no sistema, à espera de apreciação pelo CEP.

Assim, na atualidade, tais controvérsias levaram à discussão de múltiplas perspectivas: muitos pesqui- 
sadores admitem a possibilidade de criar diferentes sistemas de revisão ética em pesquisa envolvendo seres humanos, enquanto outros não reconhecem a autoridade moral do sistema ético vigente no Brasil, argumentando a favor da responsabilidade individual de cada pesquisador. Esses últimos defendem que a ética a ser considerada pelos pesquisadores deve advir dos códigos de ética profissional, os quais costumam especificar as boas práticas e as condutas éticas a serem exercidas no âmbito de cada profissão. Acreditamos que a observância e a prática das normas expressas nos códigos de ética profissionais são importantes para qualquer profissional no exercício de sua profissão e em seu fazer científico; isso, porém, não substitui o controle social em pesquisa realizado pelo Sistema CEP/Conep.

No que concerne à regulamentação, percebe-se que a revisão da Resolução 196/1996 ${ }^{1}$, consubstanciada na Resolução 466/2012 ${ }^{4}$, não trouxe todos os avanços esperados pelas mais diversas áreas do conhecimento, o que denota que as alterações foram apenas pontuais, conforme relatam Guerriero e Minayo ${ }^{21}$. Talvez uma das maiores contribuições dadas pela Resolução 466/2012 às ciências humanas e sociais seja a previsão de elaboração de resolução complementar para atender às especificidades de pesquisas nessas áreas. Nesse sentido, em 2013 foi criado um grupo de trabalho (GT) para sua elaboração, contando com representantes não só da Conep, mas também de outras associações e sociedades de pesquisa em diversas áreas do conhecimento: Associação Brasileira de Antropologia (ABA), Associação Nacional de Pesquisa e Pós-Graduação em Psicologia (Anpepp), Associação Brasileira de Ensino e Pesquisa em Serviço Social (Abepss), Associação Nacional de Pós-Graduação e Pesquisa em Educação (ANPEd), entre outras ${ }^{22}$. Esse GT realizou reuniões quinzenais entre 3 de fevereiro e 29 de maio de 2014, com base em seis pontos norteadores:

1) inclua todas as pesquisas em CHS [ciências humanas e sociais], entendidas como aquelas baseadas na epistemologia e nas metodologias dessas ciências, independentemente de sua área temática ou das questões empíricas envolvidas;

2) seja mais educativo do que fiscalizador e controlador;

3) atenha-se às implicações e consequências da prática de pesquisa para os sujeitos pesquisados, sem intrusão sobre questões metodológicas e epistemológicas dos projetos, sujeitas à avaliação pelas esferas acadêmicas convencionais;
4) reconheça diferentes níveis de "risco" (ou de "necessidade de proteção"), com implicações diferentes para a tramitação dos processos de autorização;

5) reconheça o caráter processual e dialógico da relação de pesquisa, sem exigências formais inadequadas para a comprovação a priori dos bons procedimentos;

6) institua-se um sistema de avaliação bem sumário e ágil para as pesquisas com "risco mínimo", com o escalonamento da atenção nos níveis mais complexos ou duvidosos, de forma a garantir que o sistema não se torne um impedimento burocrático para a realização das pesquisas em $\mathrm{CHS}^{23}$.

De acordo com Mainardes ${ }^{22}$, ao longo de suas reuniões, o GT elaborou uma Resolução Complementar, um formulário e um guia de orientações, os quais deverão ser discutidos pelas associações e sociedades que o integraram, encaminhados ao CNS, discutidos no $4^{\circ}$ Encontro Nacional de CEP (Encep) e disponibilizados para consulta pública ${ }^{22,24,25}$. Consideramos que essa minuta de resolução complementar traz vários avanços para as áreas de ciências humanas e sociais no âmbito do Sistema CEP/Conep, como a não obrigatoriedade do TCLE em formato escrito $e$ sua dispensa em casos pertinentes, a consideração de vários níveis de risco em pesquisa e sua especificação, a distinção entre dano material e imaterial, a possibilidade de desafogar o Sistema CEP/Conep e o reforço à revisão ético-metodológica das ciências humanas e sociais, tomando por parâmetro as suas próprias metodologias de pesquisas. Todavia, pensamos que a minuta da resolução carece de esclarecimento em alguns pontos, dos quais elencamos seis: 1) especificar o que é considerado como diferentes níveis de precaução pela resolução; 2) precisar o que é considerado, no artigo 22 da minuta, como "etapas preliminares necessárias para que o pesquisador elabore seu projeto"; 3) elencar quais critérios serão adotados pelos CEP para a checagem de risco pela secretaria do CEP; 4) explicitar que o pesquisador cujo projeto com risco mínimo for escolhido para ser apreciado pelo CEP deverá ser imediatamente comunicado por meio da Plataforma Brasil; 5) especificar como serão tratadas as pesquisas situadas na interface entre as ciências humanas e sociais e outras áreas do conhecimento, como as ciências sociais em saúde; 6) definir se essas pesquisas responderão a essa resolução complementar ou àquelas mais voltadas para as pesquisas biomédicas.

É importante mencionar também que a definição de pesquisa envolvendo seres humanos da Resolução 466/2012 é muito ampla, e não deixa 
claro quais tipos de pesquisa envolvendo seres humanos não demandam apreciação e quais devem ser revisados pelo Sistema CEP/Conep, o que significa que esse conceito também precisa ser mais bem especificado para dirimir as dúvidas que surgem no decorrer do processo de trabalho do CEP.

Como mencionamos, no âmbito dessa discussão sobre a revisão ética de pesquisas das áreas de ciências humanas e sociais, há a proposta de elaboração de sistema específico para a revisão de projetos dessas áreas que seria separado do Sistema CEP/ Conep - portanto, sem relação com o Ministério da Saúde e com o Conselho Nacional de Saúde (CNS) - e vinculado ao Ministério da Ciência, Tecnologia e Inovação (MCTI) 11,26,27. Justifica a elaboração desse novo sistema a impossibilidade de elaborar resolução complementar a partir de uma resolução de matriz biocêntrica ${ }^{27}$. Consoante ao argumento, acreditamos que o Sistema CEP/Conep e suas resoluções devem se adaptar às necessidades das áreas de ciências humanas e sociais, no intuito de construir modelo mais inclusivo de revisão ética dos projetos de pesquisa. Para tanto, é necessária constante atualização dessas resoluções com a participação social por meio de consulta pública, o que significa reconhecer também que a revisão da Resolução 196/1996, realizada em 2012 ao converter-se na Resolução 466/2012, ficou aquém dos anseios e necessidades de boa parte da comunidade científica.

Apesar da necessidade de aprimorar o sistema SEP/Conep, a retirada ou exclusão das ciências humanas e sociais poderia fragmentá-lo, bem como distanciar as áreas acadêmicas da tão almejada transdisciplinaridade (entendida como consequência da síntese dialética proveniente da interdisciplinaridade ${ }^{9}$ ), dado que estabeleceria barreira à produção de saberes, em vez de canal de comunicação entre as diversas formas de fazer pesquisa. É importante mencionar que, no âmbito dos CEP, a interdisciplinaridade se dá por meio da correlação de olhares de pareceristas de várias áreas do conhecimento na revisão ética e discussão dos pareceres dos projetos, enquanto a transdisciplinaridade seria um passo adiante, ou seja, significaria o reconhecimento da interdependência entre saberes e a discussão plenária dos projetos descolada de pretenso paradigma ideal do fazer científico, seja ele biomédico ou não.

Nesse sentido, a elaboração de resolução complementar para as ciências humanas e sociais é consonante com a afirmação de Diniz e Guerriero de que não é necessária a elaboração de outro sistema de revisão ética. O Sistema CEP/Conep deve incorporar os diversos modos de fazer pesquisa, dado que a ética deve estar presente em todos os tipos de pesquisa, mas a sua tradução em regras de procedimento para o trabalho dos comitês deve ser diversa ${ }^{28}$.

Assim, torna-se essencial que a regulamentação da ética em pesquisa no Brasil contemple e reconheça a existência de múltiplas formas de fazer pesquisa e que diferenças na metodologia de pesquisa das áreas não biomédicas não retiram seu mérito ético, científico e social, o qual deve ser considerado pelos CEP em sua revisão ética, bem como para a devida elaboração de resolução complementar voltada para as ciências humanas e sociais. Outro aspecto igualmente relevante é a necessidade de promover a sensibilização do Sistema CEP/Conep e de seus integrantes no intuito de envidarem esforços para revisar as pesquisas em ciências humanas e sociais, tomando como parâmetro metodológico o método e as técnicas próprias dessas áreas. Isso significa que é possível a coexistência de diferentes abordagens dentro do sistema CEP/Conep, como é o caso do CEP do Instituto de Ciências Humanas da Universidade de Brasília (CEP/IH/UnB), especializado na revisão ética de pesquisas sociais e com a missão de pensar o Sistema CEP/Conep à luz das particularidades da pesquisa social, para isso restringindo seu trabalho às pesquisas qualitativas desenvolvidas com o emprego de questionários, entrevistas, surveys e observação ${ }^{29}$. De acordo com Diniz ${ }^{15}$, o CEP/ IH/UnB não é espaço de segregação das ciências humanas e sociais, e sim, lugar de revisão ética e de produção de conhecimento fundado na presunção de neutralidade disciplinar do Sistema CEP/Conep, que também tem como missão avaliar os limites e potencialidades do próprio sistema na revisão de projetos de pesquisa das áreas antes citadas.

Ademais, o CEP pode e deve utilizar as potencialidades advindas de seu caráter multiprofissional para desempenhar suas funções, empregando, portanto, abordagem transdisciplinar nas discussões plenárias e revisões éticas dos projetos. Paralelamente à progressiva consolidação de comitês de ética voltados para a análise das especificidades da área social nas instituições brasileiras, é importante estimular o ingresso de profissionais das áreas de ciências humanas e sociais nos CEP ora existentes, possibilitando a sensibilização e a capacitação progressivas de seus integrantes nos métodos e técnicas utilizados nessas áreas.

Além de fomentar essa possibilidade de repasse informal de conhecimento, é indispensável também investir na contínua capacitação dos pareceristas ${ }^{30-32}$, inclusive dos representantes dos 
usuários, seja no que concerne ao reconhecimento das idiossincrasias das áreas de ciências humanas e sociais, seja no que diz respeito a qualquer outro tipo de pesquisa, até mesmo biomédica, cujas peculiaridades se alteram substancialmente com as rápidas e crescentes transformações tecnológicas. A capacitação dos integrantes dos CEP pode ser realizada de quatro formas diferentes, as quais, para melhor resultado, devem coexistir de maneira complementar:

1) Pelos próprios CEP, por meio de cursos para ingresso de novos pareceristas e cursos de capacitação e atualização locais;

2) Por cursos de capacitação nacionais, que geralmente são realizados na modalidade EAD (educação à distância) e englobam pareceristas de comitês de ética de vários estados do Brasil, promovendo a interação entre integrantes dos CEP de vários locais e distintas realidades. Desses, destacamos o I Curso de Atualização à Distância em Ética em Pesquisa, realizado em 2008 pelo Instituto Anis e pela Universidade de Brasília ${ }^{33}$, e o Curso de Bioética Aplicado às Pesquisas Envolvendo Seres Humanos, promovido pela Fundação Oswaldo Cruz (Fiocruz) em parceria com a Conep e o Ministério da Saúde e realizado em duas versões, em 2012 e 2013;

3) Pela interação e aprendizado entre os pareceristas ao longo das discussões realizadas nas reuniões plenárias do CEP;

4) Pela promoção de eventos científicos que envolvam toda a comunidade acadêmica. Além de contribuírem para capacitar os membros do CEP, tais eventos auxiliam também a capacitação de pesquisadores locais, facilitando o processo de submissão dos protocolos de pesquisa ao CEP e o diálogo pesquisador-CEP.

A fim de realizar essas atividades educativas para a comunidade acadêmica e capacitar continuamente os pareceristas, o CEP precisa que a instituição que o sedia financie e forneça a infraestrutura que possibilite a promoção dos cursos e eventos científicos locais, bem como propicie condições para que os pareceristas compatibilizem o aprimoramento necessário às suas atividades no CEP com sua jornada de trabalho (notadamente no que concerne aos cursos nacionais, que em geral têm carga horária mais elevada), de modo a evitar os casos de evasão e desistência dos cursos. Cabe sugerir, ademais, que a participação nos CEP seja reconhecida pela Comissão de Assessoramento de Pessoal de Nível Superior (Capes), trazendo algum bônus aos docentes e aos programas nos quais se inserem na forma de pontuação nos relatórios de produção.

É necessário também que todas as instituições que contam com CEP incluam o trabalho realizado nesse órgão como parte da jornada de trabalho global dos pareceristas, o que facilitaria a frequência a reuniões e dinamizaria as discussões plenárias. Além disso, é imprescindível criar alternativas para favorecer a participação e permanência dos representantes dos usuários no CEP e para melhor incluí-los nos cursos de capacitação locais e nacionais. Tais alternativas poderiam ser, entre outras, a criação de estímulos para os empregadores que liberarem seus funcionários que são representantes dos usuários para as atividades relacionadas ao CEP; a elaboração, em linguagem mais simples e lúdica, de material complementar para os cursos de capacitação, focado no estudo de situações-problema, e/ ou a criação de cursos específicos para representantes dos usuários, considerando que nem todos têm curso superior.

Por fim, cabe ressaltar que a realização de atividades educativas para os membros do CEP pode contribuir para o estabelecimento de visão plural e transdisciplinar da revisão ética no âmbito do Sistema CEP/Conep, que permita aos comitês de ética apreciar também os projetos de pesquisa das ciências humanas e sociais, levando em conta suas peculiaridades e apreciando sua relevância ética, metodológica e social sem, no entanto, tentar enquadrá-los em modelo biocêntrico de pesquisa. Para responder de maneira adequada a esse desafio, o Sistema CEP/Conep precisa incrementar a análise da ética em pesquisa, considerando que a ética deve estar sempre atrelada à ciência e a seus métodos, independentemente da área do conhecimento.

\section{Considerações finais}

Diante do exposto, percebe-se que a criação de novo sistema de revisão ética em pesquisas envolvendo seres humanos levaria à fragmentação do sistema já existente, sem resolver definitivamente os problemas apontados pelas áreas não biomédicas do conhecimento científico. Além de fragilizar ainda mais os participantes das pesquisas, tal fragmentação constituiria empecilho à transdisciplinaridade, à construção de pontes entre as muitas formas de fazer ciência, como propõe a reflexão bioética. A ampliação e concomitante aprofundamento do Sistema CEP/Conep a fim de incorporar as necessidades das 
áreas humanas e sociais, ao contrário, evitaria nova divisão e compartimentação do saber, que em nada contribui para o estabelecimento de parâmetros interdisciplinares capazes de favorecer a construção de uma sociedade mais inclusiva e justa. Esse aspecto demanda o fortalecimento do Sistema CEP/ Conep em sua totalidade, de tal modo que a realização de adequações não deva se restringir apenas às resoluções e/ou à criação de novas resoluções complementares, mas perpassar os vários aspectos que compõem sua dinâmica de funcionamento, inclusive aqueles referentes ao âmbito institucional, à capacitação de seus integrantes, ao seu papel educativo, bem como à Plataforma Brasil, que precisa ser melhorada para atender a contento às pesquisas que não se enquadram no modelo de formulário atualmente disponível para preenchimento on-line na plataforma, que é voltado para pesquisas clínicas e de testes de medicamentos.

Nota-se também que sistema único de revisão ética em pesquisa não inviabiliza a criação de CEP voltados para a pesquisa em ciências humanas e sociais, como o da UnB, e que a elaboração de resolução complementar, focada nas particularidades das ciências humanas e sociais, representa importante ganho para o Sistema CEP/Conep, visto que poderá colaborar para dirimir dúvidas surgidas durante a apreciação ética de projetos de pesquisas nessas áreas, principalmente em comitês que apresentam perfil mais voltado para as áreas não biomédicas. Uma resolução específica também poderá disseminar o conhecimento e propiciar o entendimento dos pesquisadores dessas áreas sobre o processo de submissão e revisão ética de seus projetos de pesquisa pelos CEP, facilitando assim o diálogo pesquisador-CEP.

Além disso, os CEP precisam ser mais flexíveis e atentar para que não se tornem engessados e burocráticos, empregando as resoluções como "tábua de salvação" e definindo determinado modo de fazer pesquisa como único e verdadeiro. Existem múltiplas formas de fazer pesquisa e, na ciência, a verdade é algo que se busca, mas que nunca, de fato, se alcança; pois a ciência não é inerte, está sempre avançando, modificando-se e questionando a si mesma. E, por mais amplas que sejam as resoluções e por mais que se crie um infindável número de resoluções complementares específicas, elas nunca darão conta de todas as dúvidas e situações que surgirão nos CEP, devido às próprias características da ciência e à sua amplitude. Em caso de dúvidas não contempladas pelas resoluções, o comitê de ética deve discutir a situação sem perdê-la de vista, con- siderando também o mérito ético-metodológico, a relevância social, a relação risco-benefício para os participantes da pesquisa, e, caso persistam as dúvidas, deve solicitar a apreciação do projeto de pesquisa por parecerista ad hoc da área do projeto que suscitou as dúvidas.

Para que o CEP se flexibilize e assuma a postura de orientador e corresponsável pelos projetos em análise, sem atuar como mero censor burocrático, que seja capaz de revisar eticamente os projetos que a ele são submetidos com resolutividade e qualidade, é imprescindível que se formem mais comitês de ética em instituições com grande número de projetos de pesquisa em demanda de análise. Além disso, cada instituição que realiza pesquisas envolvendo seres humanos, seja ela pública ou particular, deve contar com seu CEP, e seus membros devem ter adequada capacitação para compô-lo, pois é indispensável que o aumento do número de comitês de ética esteja atrelado ao incremento da qualidade de suas atividades. Disso se depreende que iniciativas como o Curso de Aperfeiçoamento em Bioética Aplicada às Pesquisas Envolvendo Seres Humanos, fruto de parceria entre a Fiocruz e a Conep, são excelentes para propiciar a qualificação da qual os CEP necessitam, mas ao mesmo tempo devem ser criadas estratégias de incentivo para que os pareceristas dos CEP ingressem e permaneçam no curso de aperfeiçoamento e para que esse seja mais acessível às necessidades de aprendizado bioético dos representantes dos usuários.

Além disso, o próprio Sistema CEP/Conep precisa criar alternativas de incentivo à frequência e permanência nas reuniões, bem como à eficiência dos pareceristas dos CEP, uma vez que se trata de trabalho voluntário. Situações como essas têm sido apontadas como problema por vários estudos, pois são identificadas como limitantes das atividades dos CEP. Alternativas a essas limitações seriam: cômputo das horas trabalhadas no CEP como horas de trabalho efetivo na instituição; reconhecimento institucional e curricular do trabalho no CEP, que passaria a contar pontos para progressão na carreira e em outros sistemas de mérito científico.

Ainda no campo institucional de funcionamento dos CEP, é interessante afirmar que a Plataforma Brasil representa importante avanço para o aumento da agilidade e resolutividade do Sistema CEP/Conep, não apenas para melhorar o acompanhamento dos projetos de pesquisa aprovados, mas também para reduzir a burocracia. Todavia, essa plataforma ainda carece de melhorias em sua estrutura, vez que ainda está basicamente voltada para pesquisas em áreas 
biomédicas. Disso se infere que os CEP mais focados em pesquisas nas áreas de ciências humanas e sociais, assim como em tantas outras áreas do conhecimento que não seguem o modelo biomédico de pesquisa, devem ter sensibilidade para orientar os pesquisadores na adaptação da formatação da plataforma às especificidades de seus estudos. Isso, obviamente, não descarta de maneira nenhuma a necessidade de melhoria da plataforma e de criação de caminhos variados na própria plataforma para as diversas áreas do conhecimento, mas apenas atende às necessidades atuais de uso dos pesquisadores, os quais não dispõem de tempo hábil para esperar as modificações a serem realizadas.

Finalmente, é importante deixar claro que os CEP não devem ser entendidos pelos pesquisadores como filtro ético que se outorga o direito de determinar o que é ou não ético. Ao contrário, o CEP deve ser compreendido como órgão que se preocupa com as implicações sociais e ambientais de estudos científicos, voltado a exercer o controle social das pesquisas, tendo ainda como papel adicional lembrar à comunidade científica que a ciência não é autônoma. Isso significa que a ética profissional das mais diversas áreas do conhecimento não deve ser contrária à ética defendida pelo CEP. A ética profissional e a ética em pesquisa defendida pelo CEP são complementares e devem ser parceiras durante toda e qualquer atividade de pesquisa envolvendo seres humanos, seja na área biomédica, seja nas ciências humanas e sociais. Portanto, os pesquisadores devem empregar, em sua prática, um contínuo fazer ético em pesquisa, no qual o comitê de ética em pesquisa não representa um obstáculo a ser transposto, e sim um parceiro que ajuda a alcançar os mais altos padrões éticos.

\section{Referências}

1. Brasil. Conselho Nacional de Saúde. Resolução no 196, de 10 de outubro de 1996. [Internet]. 1996 [acesso 20 set 2008]. Disponível: conselho.saude.gov.br/docs/Reso196.doc

2. Brasil. Conselho Nacional de Saúde. Resolução no 1, de 1988. [Internet]. 1988 [acesso 20 set 2008]. Disponível: http://conselho.saude.gov.br/resolucoes/1988/reso01.doc

3. Brasil. 10 Encontro Extraordinário dos Comitês de Ética em Pesquisa fecha documento sobre a revisão da Resolução 196/96. Ministério da Saúde/Departamento de Ciência e Tecnologia (Decit). [Internet]. 2012 [acesso 27 jun 2014]. Disponível: http://conselho.saude.gov.br/ultimas_ noticias/2012/25_set_I_encontro_extraordinario_conep.html

4. Brasil. Conselho Nacional de Saúde. Resolução no 466 , de 12 de dezembro de 2012. Diário Oficial da União, no 12, 13 jun 2013, p. 59. Seção 2. [Internet]. [acesso 24 jun 2014]. Disponível: http:// conselho.saude.gov.br/resolucoes/2012/Reso466.pdf

5. Brasil. Conselho Nacional de Saúde. Resolução no 446, de 11 de agosto de 2011. [Internet]. 2011 [acesso 9 jun 2014]. Disponível: http://conselho.saude.gov.br/web_comissoes/conep/aquivos/ resolucoes/resolucoes.htm

6. Freitas CBD. Os comitês de ética em pesquisa: evolução e regulamentação. Rev. bioét. (Impr.). 2009;6(2).

7. Freitas CBD. O sistema de avaliação da ética em pesquisa no Brasil: estudo dos conhecimentos e práticas de lideranças de comitês de ética em pesquisa [tese]. São Paulo: Universidade de São Paulo, Faculdade de Medicina; 2006.

8. Sistema Nacional de Informação sobre Ética em Pesquisa envolvendo Seres Humanos. Por que o Sisnep foi criado? [Internet]. [acesso 4 jun 2014]. Disponível: http://portal2.saude.gov.br/sisnep/ pesquisador

9. Weil P, D’Ambrosio U, Crema R. Rumo à nova transdisciplinaridade: sistemas abertos de conhecimento. São Paulo: Summus; 1993.

10. Rabinow P. Representações são fatos sociais: modernidade e pós-modernidade na antropologia. In: Biehl JG, organizador. Antropologia da razão: ensaios de Paul Rabinow. Rio de Janeiro: Relume Dumará; 1999. Cap. 4, p. 71-108.

11. De La Fare M, Machado FV, Carvalho ICM. Breve revisão sobre regulação da ética em pesquisa: subsídios para pensar a pesquisa em educação no Brasil. Práxis Educativa. 2014;9(1):247-83.

12. Oliveira LRC. A antropologia e os seus compromissos ou responsabilidades éticas. In: Fleischer $\mathrm{S}$, Schuch P, organizadoras. Ética e regulamentação na pesquisa antropológica. Brasília: Letras Livres; 2010. p. 25-38. Em coedição com Editora da UnB.

13. Porto $D$. Relato de uma experiência concreta com a perspectiva das ciências da saúde: construindo o anthropological blues. In: Fleischer S, Schuch P, organizadoras. Op. cit. p. 101-26.

14. Diniz D, Sugai A. Ética em pesquisa: temas globais. In: Diniz D, Sugai A, Guilhem D, Squinca $F$, organizadoras. Ética em pesquisa: temas globais. Brasília: Letras Livres; 2008. Em coedição com Editora da UnB. p. 17-8.

15. Diniz D. A pesquisa social e os comitês de ética no Brasil. In: Fleischer S, Schuch P, organizadoras. Op. cit. p. 183-92. 
16. Barbosa AS. Entraves e potencialidades dos comitês de ética em pesquisa (CEP) das universidades estaduais da Bahia [dissertação]. Jequié: Universidade Estadual do Sudoeste da Bahia, Programa de Pós-Graduação em Enfermagem e Saúde; 2010.

17. Barbosa AS, Boery RNSO, Boery EN, Gomes Filho DL, Sena ELS, Oliveira AASO. A Resolução 196/96 e o sistema brasileiro de revisão ética de pesquisas envolvendo seres humanos. Rev. bioét. (Impr.). 2011;19(2):523-42.

18. Freitas CBD, Novaes HMD. Lideranças de comitês de ética em pesquisa no Brasil: perfil e atuação. Rev. bioét. (Impr.). 2010;18(1):185-200.

19. Conselho Nacional de Sa HM. Comissão Nacional de Ética em Pesquisa. CEP ativos por macrorregiões. [Internet]. 2014 [acesso 4 jun 2014]. Disponível: http://conselho.saude.gov.br/ web_comissoes/conep/aquivos/MAPA_CEP_ATUALIZADO_2014.jpg

20. Brasil. Ministério da Educação. Instituições de Educação Superior e Cursos Cadastrados. Sistema de Regulação do Ensino Superior - e-MEC. [Internet]. [acesso 4 jun 2014]. Disponível: http:// emec.mec.gov.br

21. Guerriero ICZ, Minayo MCS. O desafio de revisar os aspectos éticos das pesquisas em ciências sociais e humanas: a necessidade de diretrizes específicas. Physis. 2013;23(3):763-82

22. Mainardes J. Seção temática: ética na pesquisa. Práxis Educativa. 2014;9(1):197-8.

23. Associação Nacional de Pós-Graduação e Pesquisa em Ciências Sociais. Por uma regulamentação específica da ética em pesquisa nas ciências humanas e sociais. [Internet]. 2014 [acesso 9 jun 2014]. Disponível: http://portal.anpocs.org/portal/index.php?option=com_ content\&view=article\&id=1149:por-umaregulamentac ao-especifica-da-etica-em-pesquisa-nasciencias-humanas-e-sociais-\&catid=1136: destaqu es\&ltemid=433

24. Grupo de Trabalho de Ciências Humanas e Sociais da Conep. Minuta da Resolução Complementar em Ciências Humanas e Sociais. [Internet]. 2014 [acesso 2 nov 2014]. Disponível: http://www. portal.abant.org.br/images/Noticias/minuta_resolu\%C3\%A7\%C3\%A3o_\%C3\%A9tica_pesquisa_ CHS.pdf

25. Conselho Nacional de Saúde. Comissão Nacional de Ética em Pesquisa. Carta circular no 100/2014 Conep/CNS/GB/MS. Texto informativo sobre GT Pesquisa em Ciências Sociais e Humanas Conep. 2014 [acesso 2 nov 2014]. Disponível: http://conselho.saude.gov.br/web_comissoes/ conep/aquivos/CartaCircular100-2014.pdf

26. Carvalho ICM, Machado FV. A regulação da pesquisa e o campo biomédico: considerações sobre um embate epistêmico desde o campo da educação. Práxis Educativa. 2014;9(1):209-34.

27. Duarte LFD. Comitê de ética em pesquisa nas ciências humanas. Primeira reunião de GT da Conep visando à elaboração de "resolução complementar" à Resolução 466/12. [Internet]. 2014 [acesso 4 jun 2014]. Disponível: http://www.portal.abant.org.br/index.php/comite-de-etica-empesquisa-nas-ciencias-humanas

28. Diniz D, Guerreiro ICZ. Ética na pesquisa social: desafios ao modelo biomédico. Reciis - R. Eletr. de Com. Inf. Inov. Saúde. 2008;2(Supl.1):78-90.

29. Universidade de Brasília. Comitê de Ética em Pesquisa do Instituto de Ciências Humanas. Apresentação. [Internet]. 2014 [acesso 4 jun 2014]. Disponível: http://www.cepih.org.br

30. Barbosa AS, Boery RNSO, Ferrari MR. Importância atribuída ao comitê de ética em pesquisa (CEP). Rev. Bioética y Derecho. 2012;26:31-43.

31. Barbosa AS, Boery RNSO, Boery EN, Gomes Filho DL. Caracterização dos integrantes de comitês de ética em pesquisa. Rev. bioét. (Impr.). 2012;20(1):164-74.

32. Barbosa AS, Boery RNSO, Ferrari MR. Desenvolvimento da dimensão educacional dos comitês de ética em pesquisa (CEPs). Acta bioeth. 2012;18(1):83-91.

33. Diniz D, Sugai A, Guilhem D, Squinca F. Agradecimentos. In: Diniz D, Sugai A, Guilhem D, Squinca F, organizadoras. Op. cit. p. 7-8.

\section{Participação dos autores}

Adriana Silva Barbosa contribuiu com a redação de todas as partes do texto. Carlos Montero Corrales contribuiu com a redação da introdução. Marcos Silbermann contribuiu com a redação de parte da discussão (item "Controvérsias na revisão ética de pesquisas em ciências humanas e sociais").

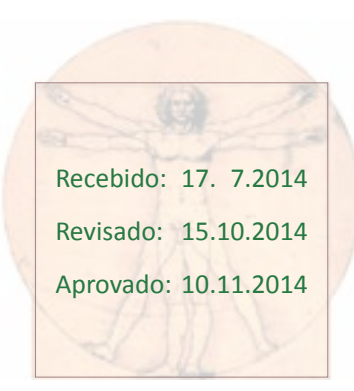

